AC 2012-5056: ASSESSMENT OF A NEW DESIGN STEM COURSE SEQUENCE

Dr. Robert G. Ryan, California State University, Northridge

Robert Ryan is an Associate Professor at California State University, Northridge. He has more than 20 years of experience teaching a wide variety of mechanical engineering courses, including fluid mechanics, heat transfer, mechanical measurements, and senior design. He is currently serving as Assessment Coordinator for the Mechanical Engineering Department's ABET review process. Ryan earned his Ph.D. degree from University of California, Los Angeles, in 1994. 


\title{
Assessment of a New Design Stem Course Sequence
}

\begin{abstract}
In Fall 2009, the Mechanical Engineering Department at California State University, Northridge implemented significant changes to the curriculum by creating a new course sequence focused on design. The course sequence is distributed throughout the four years of the program, and culminates in the traditional capstone senior design course. One of the features of the new sequence was the requirement of a team project in each course, including oral design reviews documenting the projects' progress. Enabling our students to continuously develop and demonstrate skills related to design and communication was the main incentive behind the changes to the design course sequence.
\end{abstract}

As part of our institution's ABET assessment process, the author attended oral design reviews in all of the courses in the design sequence over the course of a single semester, in order to get a "snapshot" of the quality of these presentations. The presentations were evaluated for both design content and effectiveness of communication, using a rubric which was developed and approved by the Department Faculty. Where possible, both Preliminary Design Reviews and Critical Design Reviews were evaluated, in order to assess the entire design process from beginning to end. All evaluations were performed independently by the author to provide consistency in scoring.

Analysis of the evaluation data aims to show that our students significantly enhance their design and communication skills as they progress through the mechanical engineering program. Also, perceived weaknesses are used to recommend strategies for continuous improvement to this course sequence, as required by ABET's Criterion Four.

Introduction

Reform of the design curriculum in the mechanical engineering program at California State University, Northridge has been an ongoing effort that dates back to the self-study document written for the 2001 ABET review. Our initial effort at curricular reform focused on including design methodology, manufacturing processes, and more comprehensive instruction in the use of SolidWorks software, and introduced students to the Conceive-Design-Implement-Operate (CDIO) framework as a template for the practice of engineering. A detailed description of the curricular changes and some preliminary assessment results from the 2005 time frame were given by Ryan and Ho in $2006^{1}$.

After these program changes were offered for several years, and feedback was collected via the Department's assessment process, it was felt that a more comprehensive approach toward 
revision of the design sequence was required. A faculty committee was formed which included three full time faculty as well as two experienced part-time faculty who had been teaching courses related to design; the committee's charge from the Department Chair was to create a new design stem of courses to support our program's learning outcomes, without being constrained by the format of the existing design course sequence. The committee used the Conceive-DesignImplement-Operate $(\mathrm{CDIO})^{2}$ framework as a template for this new design sequence.

The committee defined the Skills, Knowledge, and Attributes (SKA's) required by students in the area of mechanical design. These SKA's were divided into three categories: technical knowledge; software skills; and personal, professional, and interpersonal abilities. The next step was to look at our existing course structure to see if the SKA's were being adequately supported. Deficiencies were identified and ultimately a new sequence of courses was developed to address these concerns. The specifics of this process and its outcomes were described by Ho and Ryan ${ }^{3}$.

The result of these changes (effective for the Fall 2009 semester) was a clearly defined design stem of courses (ME 186, 286, 386, and 486) which extends uniformly throughout the curriculum. Each course in the design stem is a prerequisite for the next course in the sequence. Each course includes application of the SKA's through a design project, performed by a student team and communicated via oral presentations and written reports. The unifying concept was that these projects would provide students with multiple applications of their design skills, and the projects would become more complex as the students were taught additional SKA's. It was immediately clear that assessment of student performance on these design projects would become a key component of our ABET assessment process.

Rubrics for the evaluation of design presentations and reports were developed in order to provide a uniform template for faculty expectations for effective communication during design reviews. The rubric development followed the characteristics suggested by Cooney ${ }^{4}$ : consistency with course objectives, explicit scoring criteria, a simple form for recording scores, and a one page summary of criteria for easy reference for reviewers during the rating process.

The design of the rubrics began with the definition of performance criteria for oral presentations and written reports. Criteria for oral presentations are shown in Table 1. Generally these criteria can be divided into ones related to communication skills, and ones related to design methodology and process. (These two groups of criteria directly map to two of our program learning outcomes.) Our approach for assessment attempts to emphasize the evaluation of the design process, based on the belief that if students learn and practice a consistent design methodology throughout their undergraduate program, they will be well prepared for developing good designs as professionals.

A form was developed for the assignment of a rating of 1 (Needs Improvement) to 4 (Excellent) for each performance criterion. Also, a column was provided for a "weighting factor" for each 


\begin{tabular}{|c|c|}
\hline Performance Criteria Description & Code Used in Charts \\
\hline $\begin{array}{l}\text { Organization - Presentation is well organized with respect to overall } \\
\text { structure (e.g. appropriate outline with introduction, main content with } \\
\text { supporting materials, transitions, conclusion) }\end{array}$ & ORG \\
\hline $\begin{array}{l}\text { Body Language - Effective use of eye contact, facial expressions, body } \\
\text { movements to express message }\end{array}$ & $\mathrm{BL}$ \\
\hline $\begin{array}{l}\text { Vocal Variety - Effective use of voice (e.g., volume, clarity, inflection, } \\
\text { pace of speaking, uplifting) }\end{array}$ & $\mathrm{VV}$ \\
\hline $\begin{array}{l}\text { Poise and Professionalism - Presenter is poised and professional in } \\
\text { appearance, posture, and gestures }\end{array}$ & $\mathrm{PP}$ \\
\hline $\begin{array}{l}\text { Transition between Presenters - Transitions to the next presenter are } \\
\text { smooth and effective }\end{array}$ & TBP \\
\hline $\begin{array}{l}\text { Use of Presentation Media - Effectiveness of use of media (e.g., graphics, } \\
\text { CAD models, handouts, video clips, prototype, physical mockups) and } \\
\text { their formats (e.g., font, color, units) }\end{array}$ & MED \\
\hline $\begin{array}{l}\text { Questions and Answers - Questions are answered accurately and concisely } \\
\text { if the presenter(s) knows the answer, or handled appropriately if the } \\
\text { presenter(s) doesn't know the answer, or taken as opportunity to delve } \\
\text { deeper into the topic }\end{array}$ & QA \\
\hline $\begin{array}{l}\text { Adherence to Time Limit - Presentation delivered within the allowed time } \\
\text { limit }\end{array}$ & TL \\
\hline $\begin{array}{l}\text { Problem Definition - A clearly stated design problem definition is } \\
\text { presented (e.g. what need(s) does this design meet, what are important } \\
\text { constraints, etc.) }\end{array}$ & PDEF \\
\hline $\begin{array}{l}\text { Goals/Criteria - Design goals, criteria, and functional requirements are } \\
\text { clearly defined }\end{array}$ & $\mathrm{G} / \mathrm{C}$ \\
\hline $\begin{array}{l}\text { Concept Evaluation - Design alternatives considered are presented, and a } \\
\text { clear methodology is used for the evaluation of alternatives (e.g. use of } \\
\text { design matrix for rating of alternatives with respect to goals/criteria, and } \\
\text { discussion of technical risks and risk countermeasures) }\end{array}$ & CEV \\
\hline $\begin{array}{l}\text { Analysis - Ability of design to meet the functional requirements is } \\
\text { supported by the required analysis (this will vary with level of the class, but } \\
\text { could include calculations for weight, cost, stress safety factors, FEA } \\
\text { results, etc.) }\end{array}$ & AN \\
\hline $\begin{array}{l}\text { Team Organization - A well defined team organization is presented (e.g. } \\
\text { team leaders are identified, responsibilities of each team member are } \\
\text { defined, etc.) }\end{array}$ & TORG \\
\hline $\begin{array}{l}\text { Budget/Schedule - If appropriate, a project budget and schedule are clearly } \\
\text { described using appropriate tools (e.g. Gantt chart, spreadsheet, etc.) }\end{array}$ & $\mathrm{B} / \mathrm{S}$ \\
\hline
\end{tabular}

Table 1 Performance Criteria for Oral Presentations 
performance criterion, to range from 0 to 3, which can be assigned by the course instructor based on the importance of that criterion to the particular project. The rating given for each performance criterion is multiplied by the weighting factor, and then the weighted scores are summed over all the criteria to come up with a total score. Weighting factors are a useful way to customize a rubric for different assignments or courses, as noted by Kellogg et $\mathrm{al}^{5}$. The weighting factors allow the rubrics to be effective for different courses, instructors, and program level while still adhering to a single list of performance criteria. The rubrics were beta-tested in different courses with different reviewers during the Fall 2009 semester to ensure their effectiveness $^{6}$.

The current study was inspired by our program's upcoming ABET accreditation visit. The revisions in our design curriculum have been our most important program changes since our last visit, and consequently an assessment of the effectiveness of the revisions is a key component of our self-study report. The methodology used to collect the results reported in this paper are discussed in the next section.

Methodology

The author is the Mechanical Engineering Department's Assessment Liaison, which at our institution confers responsibility for reporting assessment efforts to a university level committee, in addition to coordinating ABET activities with other Assessment Liaisons within the College of Engineering and Computer Science. Hence, the author was assigned the task of attending and reviewing oral design presentations during the Fall 2011 semester, in order to obtain a "snapshot" of student performance at each level of the design course sequence. The use of a single reviewer for all presentations included in the study eliminated variation among multiple reviewers. While desirable, the use of a consistent set of multiple reviewers for all presentations was not possible due to schedule constraints. It is worth noting that the author has taught the senior design capstone course for several years, and is thus very familiar with the recent history of student performance in this course.

A summary of the oral design project presentations which were attended and reviewed is as follows:

- Six projects in ME 186 (Computer-Aided Design)

- Nine projects in ME 286 (Mechanical Design)

- Five projects in ME 386 (Computer-Aided Analysis and Design)

- Four projects in ME 486 (Senior Design)

For the senior design course, both Preliminary Design Reviews (PDR's) and Critical Design Reviews (CDR's) were evaluated.

The course instructor is responsible for establishing weighting factors for each performance criterion, and sharing these with the students so that they are aware of the priorities assigned in 
the grading process. If a criterion was assigned a zero weighting factor, then it was not rated. It's worth noting that in addition to the author, the course instructor (and in some cases additional faculty or graduate students) used the rubric to rate the presentations, and it was up to the course instructor to determine how these ratings were used for course grading purposes. All of the ratings discussed in this paper are the "unweighted" values assigned by the author, so that appropriate comparisons can be made among the different courses.

Rubric Results

ME 186 (Computer-Aided Design) is a freshman course which emphasizes basic design concepts, teamwork, communication skills, and the creation of solid models and engineering drawings with SolidWorks. Class size is typically around twenty students, while each design project is performed by a team of approximately four students. The six projects evaluated were sampled from two different sections of the course. The students were provided with a list of common mechanisms to choose from. Their task was to "reverse engineer" the mechanism by creating part and assembly files to describe the geometry, and then propose design changes to improve the mechanism's performance. Project examples include a vise, an arbor press, and a ratchet wrench. In terms of defining "Goals and Criteria", they were required to define the goals and purpose of their assignment, since they were dealing with an existing design. For the "Problem Definition" and "Concept Evaluation" performance criteria, they were required to describe what the mechanism is supposed to do, and identify problems and potential fixes. The "Adherence to Time Limit" and "Analysis" criteria were not rated because the groups were not given a time limit and there was little or no analysis involved for this assignment. Figure 1 shows the average ratings (for the six projects) for each performance criterion as well as the corresponding standard deviations. The performance criteria are identified by codes defined in Table 1. 


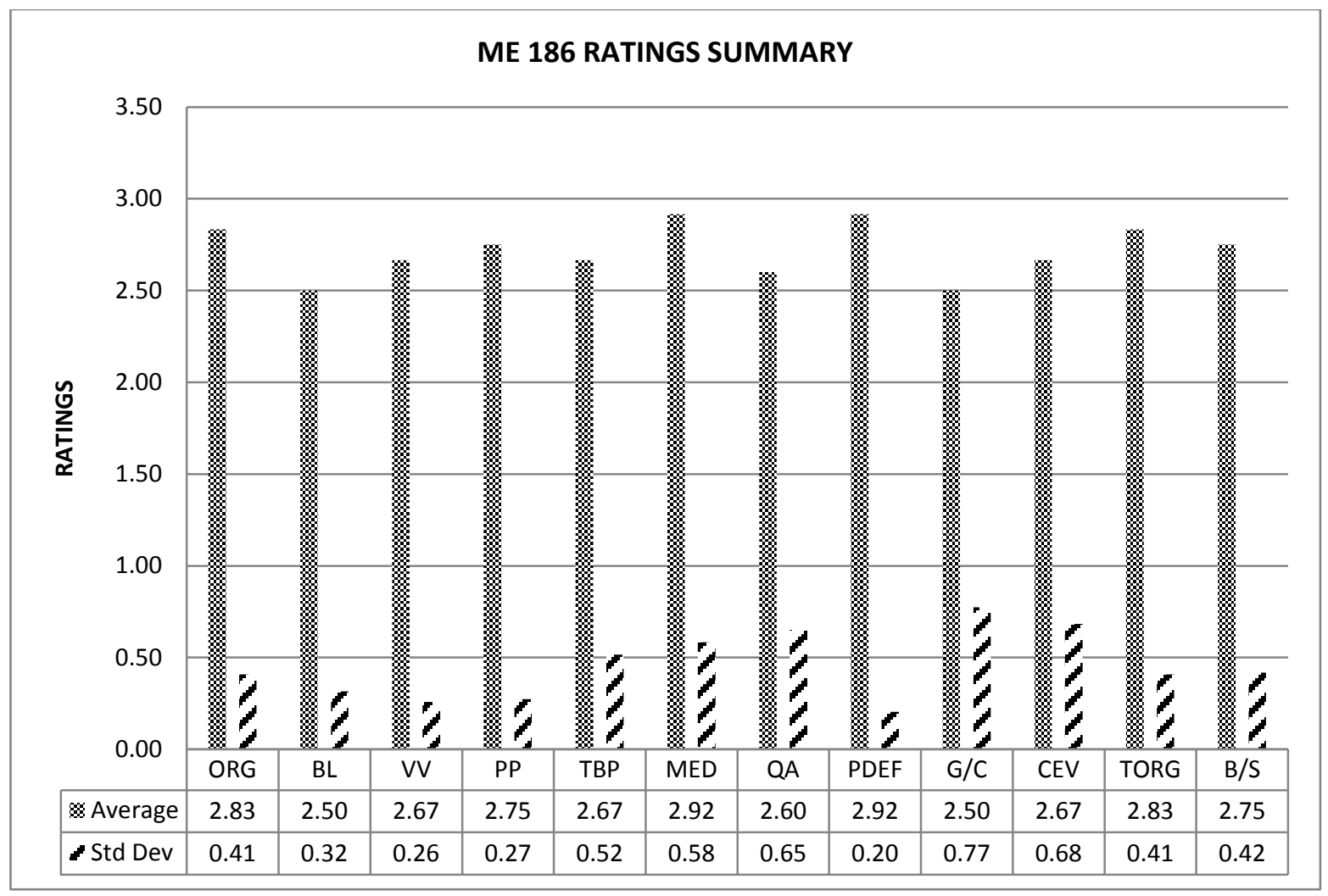

Figure 1 ME 186 Rubric Results

It can be noted that all the averages are of similar magnitude and are between 2.5 and 3 (where 2 is defined as "Fair" and 3 is "Good"). Also, the three criteria with the highest variations were "Questions and Answers", "Goals/Criteria", and "Concept Evaluation", but this was primarily due to poor scores from just one group. The presentations were generally quite effective for freshmen. Common mistakes (not just for freshmen!) included using small font sizes on charts which made them unreadable, and the tendency of some speakers to just read their slides to the audience. They were required by their instructor to talk about issues they had regarding teamwork, and how they scheduled and assigned tasks, and all of the groups seemed to genuinely learn from this experience. The majority of the students seemed to have developed good SolidWorks skills as a result of taking this course.

ME 286 (Mechanical Design) is a sophomore course which emphasizes design for manufacturing, manufacturing processes, and materials properties. Typically, the class size is about twenty-five students, and design groups consist of four to five students. In their group projects, students are expected to propose original designs of simple mechanisms, including specifications of materials, required manufacturing processes, and cost estimates. The design is documented with solid models and engineering drawings. Examples include a drink blender, tennis ball robot (for collecting balls off the court), and a portable, folding bicycle. For these projects, the cost analysis was assigned to the "Analysis" criterion, and the "Budget/Schedule" 
criterion was not rated. The rubric results for the nine projects (sampled from two different sections of the course) are shown in Figure 2.

It is immediately clear that there is significant variation in performance among the criteria. The groups generally did a poor job explaining their team organization and how the tasks were assigned. The ratings for "Concept Evaluation" were also weak. This was correlated with a lack of clearly defined design goals and criteria, and/or the lack of design alternatives which were considered prior to reaching their proposed design. The presented cost analyses were generally a good first cut, but other simple analyses (e.g. weight estimate for the folding bicycle) were lacking. It seemed that the groups in this course were sometimes lacking the teamwork skills that all of the groups seemed to show in the freshman course. This is a paradoxical result since ME 186 is a prerequisite for ME 286 (although not all students take the prerequisite as planned more on this later.)

On the positive side, the groups came up with creative designs, and in most cases seemed to be enthusiastic about their concepts.

ME 386 (Computer-Aided Analysis and Design) is a course which covers finite element analysis (FEA) using SolidWorks Simulation. It is generally taken at the same time as ME 330, which is a traditional junior level machine design course. Class size is typically about twenty students, with four students in each design group. The emphasis is not on the mathematics of FEA; rather, the focus is on using FEA properly to get accurate results, and how to interpret those results to optimize designs. Each student group presents a PDR and CDR; only the CDR was included in this study. During the PDR, the groups are expected to present the problem they are going to analyze, their proposed method of analysis, and expected results. For the CDR, the students are required to present their results, including numerical evidence that their mesh is sufficiently fine to get a converged solution. Typically the results are used to optimize the part geometry to minimize weight while maintaining an acceptable factor of safety. Some of the projects were original concepts; others were related to senior design projects (due to students taking this course late in their program, or junior students volunteering to assist with senior design projects). The five projects reviewed were all from the same section of the class. 


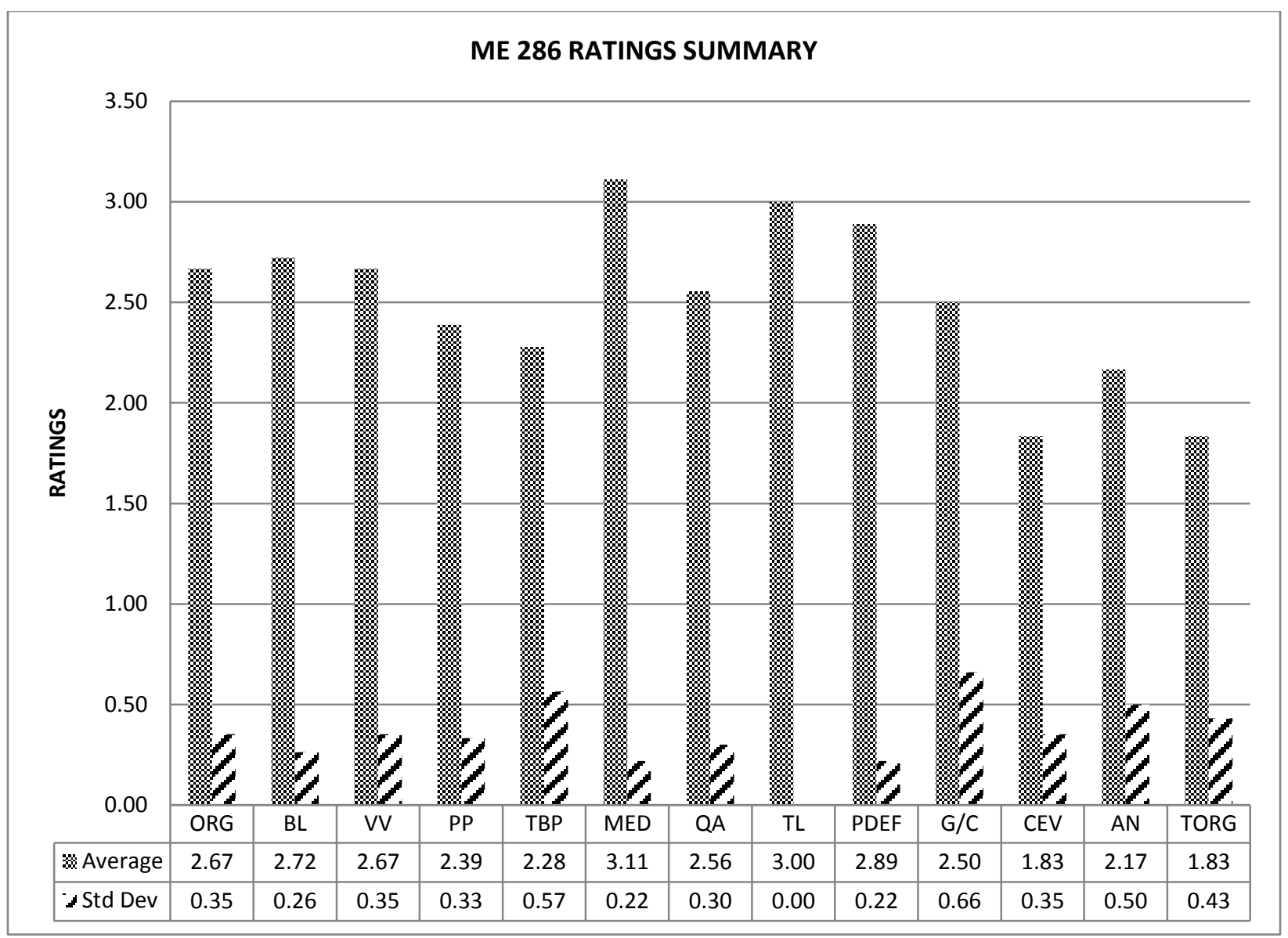

Figure 2 ME 286 Rubric Results

The rubric results for ME 386 are shown in Figure 3. The "Concept Evaluation", "Team Organization", and "Budget/Schedule" performance criteria were given zero weighting factors by the course instructor, so they were not rated .

Other than the average rating for "Use of Media", which is 3.10, most of the average ratings hover near 2.5. The lowest ratings were 2.20 and 2.30, for "Analysis" and Questions and Answers", respectively. Some of the analysis problems were related to how the input loads and restraints were determined, rather than the use of the software itself. During the Q/A session, some groups had difficulty justifying the reasons for some of their decisions related to their analysis. It should also be noted that the high standard deviation for "Goals/Criteria" was due to the lack of clarity in the purpose of the analysis (i.e. with respect to their optimization) by two of the groups. In summary, effectively using the material presented in this course is a challenge for our students, but while they clearly struggled on some issues, the projects provided a valuable experience to learn from their mistakes. Prior to the introduction of this course in our program, these kinds of mistakes were made in the capstone course. 


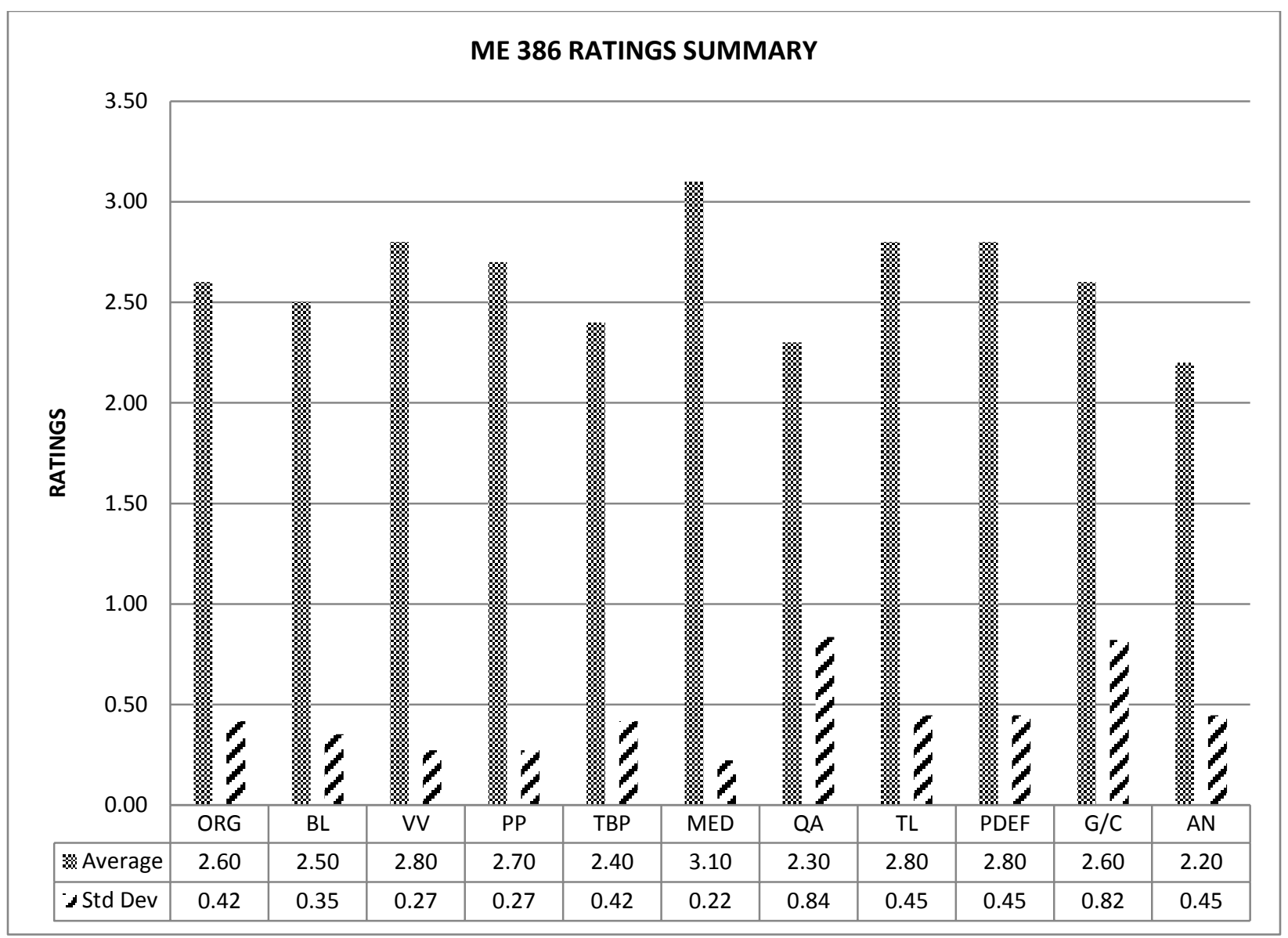

Figure 3 ME 386 Rubric Results

Figures 4 and 5 show the rubric results for the PDR and CDR for ME 486 (Senior Design). The four projects are: Formula SAE Race Car, Human Powered Vehicle, Intelligent Ground Vehicle, and Unmanned Aerial System. All of these are "Design-Build-Test-Compete" projects, involving the effort of large teams (approximately twenty students) over a two semester time period, and sometimes including students from other departments (e.g. electrical engineering or computer science). Senior design gets a lot of publicity within our Department and College, and many of the students respond to that challenge by putting enormous effort into their project work. The result has been a very respectable showing in a variety of national student design competitions.

Figure 4 shows the average ratings and associated standard deviations for the PDR's. These presentations are usually given approximately five weeks into the project. Students are expected to present alternatives for solving their design challenge, along with a logical process for selecting their preferred alternative. Their overall task is to convince the audience (particularly their faculty advisor) that they have a suitable plan for successfully completing the project within their time and budget constraints. Two performance criteria were not rated for the PDR's: "Adherence to Time Limit" (since none was defined), and "Analysis" (generally not emphasized in a PDR). The three lowest average ratings are for "Budget/Schedule", "Goals/Criteria", and 
"Questions and Answers" (also note the high variance for "Goals/Criteria"). Our senior design teams seemed to have some difficulty in defining and prioritizing clear criteria for making their design decisions. Sometimes there was inconsistency among different subgroups on the same design team with respect to design criteria. The weakness with respect to budget and schedule may just be a result of inexperience - this is typically the first important project management opportunity for these students, where the success of the project crucially depends on balancing time and money constraints. The large size of the senior design groups is also a concern, which is a function of recent enrollment trends and resource constraints, since it puts more demand on project management and allows individual students to fall through the cracks. On the positive side, the ratings for the criteria related to communication quality (i.e. on the left half of Figure 4) are all near 3, which is somewhat higher than those from Figures 1, 2, and 3.

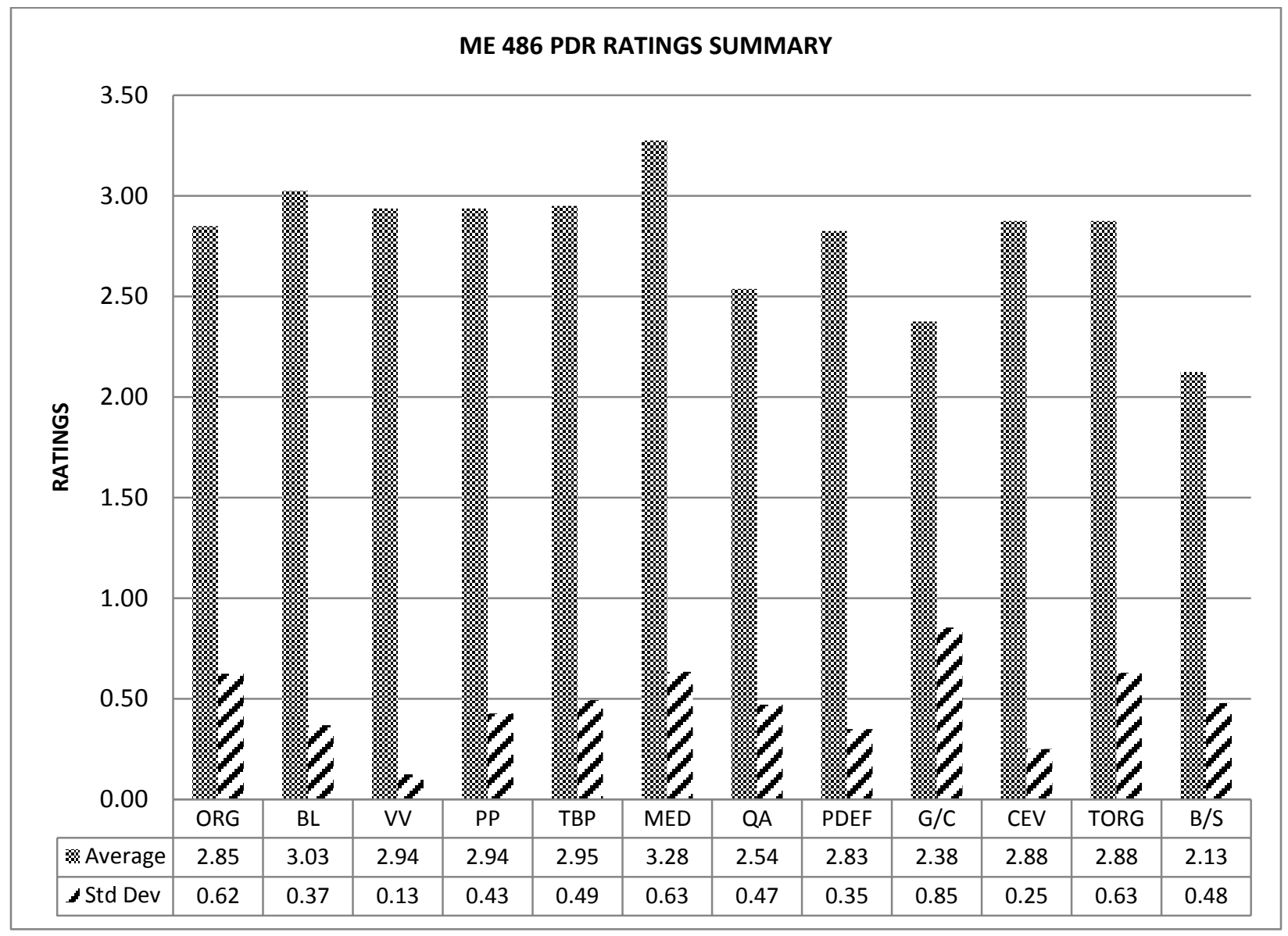

Figure 4 ME 486 PDR Rubric Results

Finally, Figure 5 shows the results for the Senior Design Critical Design Reviews. These presentations are usually given near the end of the first semester of the senior design course. The students are expected to present a finished design, including all of their CAD models, supporting analysis, complete parts list, and a detailed schedule for manufacturing and testing (which occurs in the second semester). All of the performance criteria, except for "Adherence to Time Limit", 
were included in the review. The most striking difference from the PDR scores is a significant increase in the "Budget/Schedule" rating, possibly due to feedback given during the PDR, but just as likely due to more available information as design choices were finalized and more quotes for equipment and materials were obtained. The "Goals/Criteria" rating is still low, for the same reasons as noted above with respect to the PDR ratings. The "Analysis" rating is respectable, although there are always a lot of faculty questions on issues related to analysis during the $\mathrm{Q} / \mathrm{A}$ session, which probably influenced the somewhat low "Questions and Answers" rating. Also, the average ratings for communication quality, which as noted above were near 3 for the PDR, slipped down a bit for the CDR.

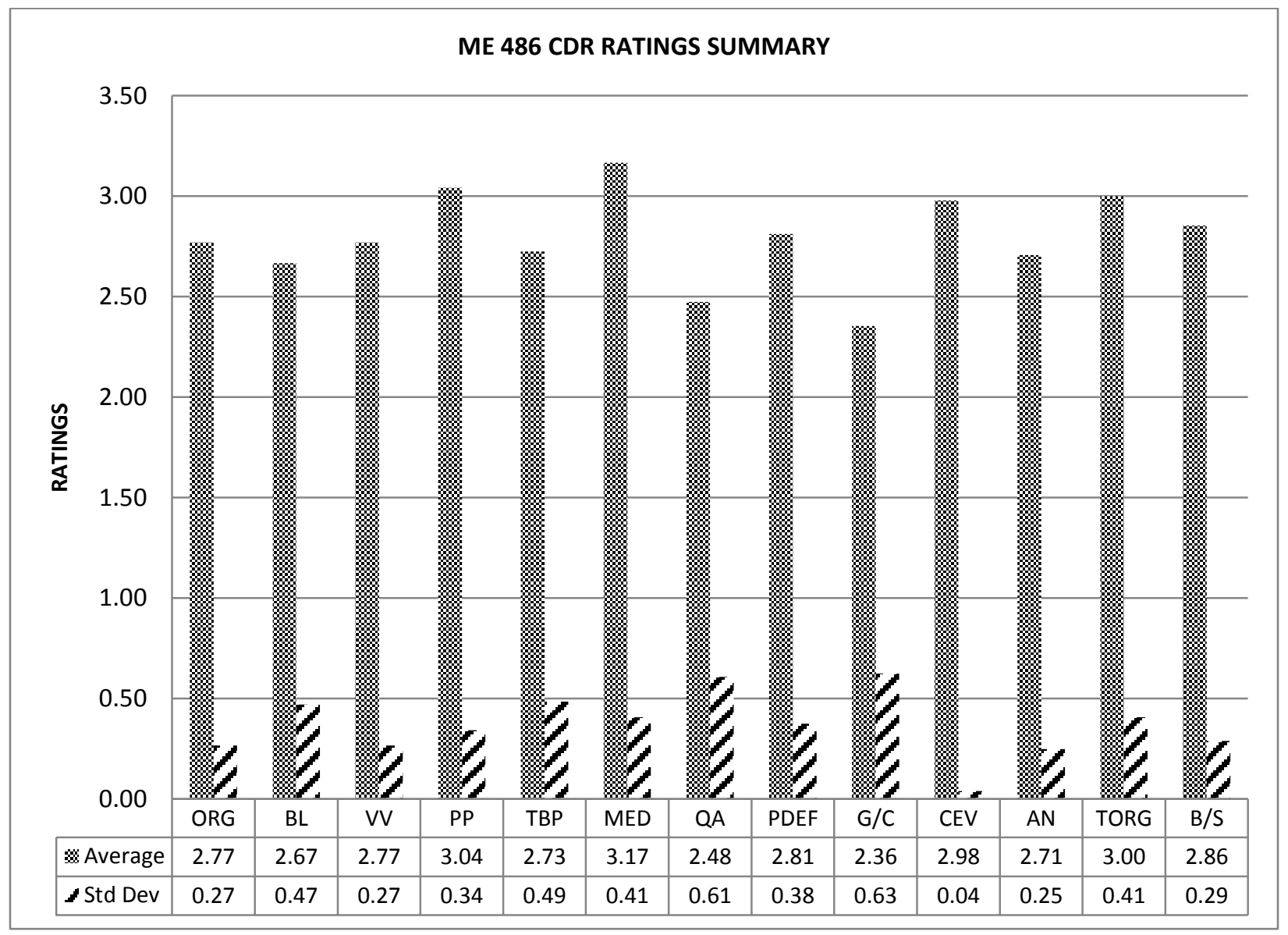

Figure 5 ME 486 CDR Rubric Results

Discussion and Interpretation

Attending and reviewing this many design reviews over a period of a few weeks was an enlightening experience for the author, and provided a clear picture regarding the continuity provided by this sequence of courses. An ideal outcome, of course, would be to see the numerical results increase continuously from freshman to senior year, and unfortunately no such 
trend is seen in these results. Even though all of the presentations are rated by the same reviewer for control purposes, it is difficult to screen out the tendency for the reviewer to expect more from upper division students, and thus rate them accordingly. Also, the projects become more complex and difficult, so that also influences how student performance is perceived. And of course, this data does not represent a longitudinal sample of the same cohort of students.

There are a few additional factors which influence year to year comparisons. Clearly, there will always be some random variation in the student quality in course sections from year to year. Also, since the latest program changes were implemented in Fall 2009, most of the students currently in senior design have not taken the entire design sequence as described in this paper. Another factor is the difficulty students are having to enroll in the courses they want, due to significantly increased demand for our program while being constrained by severe budget cutbacks. Sometimes that means that prerequisites are not enforced (i.e. courses get taken concurrently rather than in proper sequence), which is being allowed by the Department to maintain a reasonable path to graduation for our students during these difficult times. These are seen as temporary problems which should ease in the future. We also are working on plans to make this design sequence work more efficiently for our transfer students from local community colleges. Another priority is to add more senior design projects, as resources allow, to decrease the project team sizes to a more optimal level of twelve to fourteen students.

That being said, there are certain trends in the ratings that point out weak areas that must be addressed. The most obvious one is the weakness in defining clear design goals and criteria, which are then clearly used to drive design choices from available alternatives. This weakness showed up in the ME 286 ratings and carried over into senior design.

Other weaknesses, which may not be that obvious from the numerical ratings, were related to the use of PowerPoint charts. One tendency is for students to include large amounts of information on a slide, and then show it to the audience for about three seconds before moving on. Another tendency is for students to just read the text off of the slides, rather than complementing the slide content with their verbal description.

The depth of analysis used in design decisions is also a concern, which is reflected in the ratings for the "Analysis" criterion. Students often fall in love with modern computational tools like FEA and don't pay enough attention to fundamentals. Use of basic tools like free body diagrams to obtain the design loads on a part is critical for proper mechanical design; the FEA results from a beautifully meshed part means nothing if the boundary conditions are not realistic.

Looking past the numbers, it was interesting to see the types of design experiences that are now available to our students as they move through the curriculum. Since the author has taught senior design for a number of years, this project review process made it abundantly clear that the new design stem of courses will continue to improve our students' preparation for senior design. It was also clear that the progression of these design experiences is a bit different than originally 
envisioned when the program changes were developed. The original, somewhat idealized vision of the design project progression is illustrated in Figure 6. This figure reflects an ideal process, where each new project in the design course sequence incorporates everything used in the previous projects, eventually culminating in the capstone experience.

Figure 7 represents a more realistic model, which gives a better description of the interrelationship of our current program design experiences. Each design project provides additional tools and skills which are used in senior design, but by necessity, each course in the design stem focuses on a particular aspect of the design process which doesn't necessarily contain all the aspects covered in earlier projects.

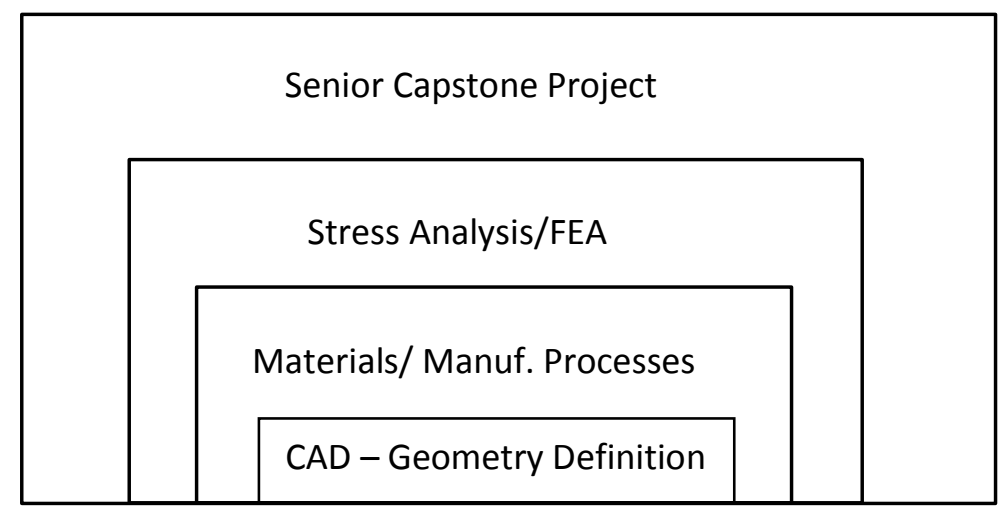

Figure 6 Ideal Mechanical Design Project Progression

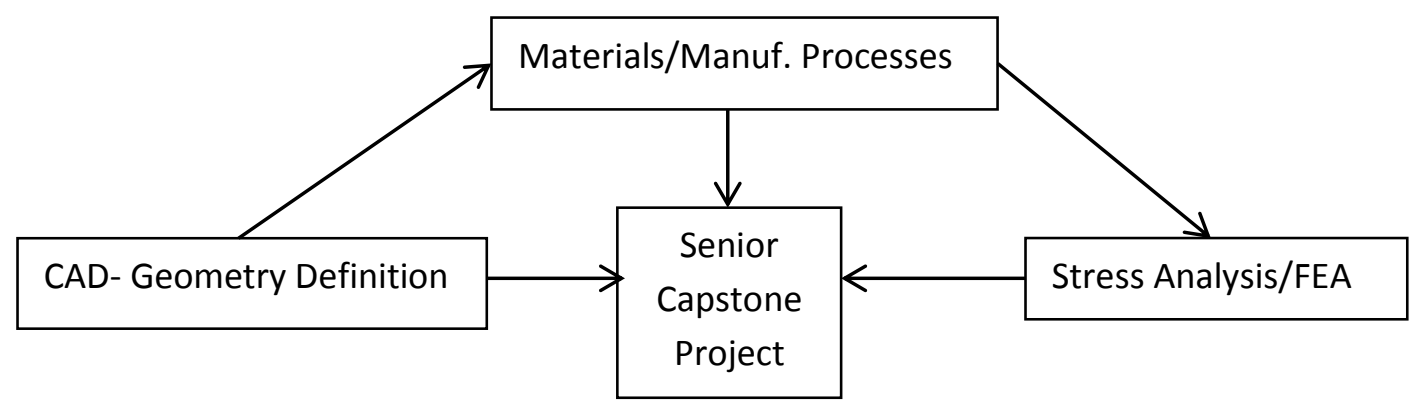

Figure 7 Design Project Progression as Implemented 


\section{Conclusions}

Evaluations of oral design reviews from courses in our program's mechanical design stem have been presented, based on data from the Fall 2011 semester. A rubric which rates fourteen performance criteria was used for the evaluations. This study was conducted to support our program's upcoming ABET visit since the courses in our design sequence have been significantly changed since the last visit. The numbers have indicated a few areas of concern, which are being shared with Department Faculty in order to improve instruction in these areas. We plan to continue this study in future years to gain a better understanding of the contribution of each course in the design sequence to the overall attainment of our program learning outcomes related to design.

Overall, the series of design projects that our students experience as they progress through the program is seen as a significant improvement from our old program structure. The result is a student who has much better preparation in design skills as he/she enters senior design, and subsequently, the engineering field.

Since our design stem course structure has proven to work well for our students, work is currently under way to optimize the entry of transfer students into our program by encouraging our local community colleges to develop articulated versions of our lower division design courses.

\section{References}

1. R.Ryan and N. Ho, "A Sophomore Design Sequence for Mechanical Engineering Students", presented at the 2006 ASEE Pacific Southwest Section Conference, Pomona, California, April 20, 2006

2. www.cdio.org

3. N. Ho and R. Ryan, "Designing a Sequence of Design Courses to Improve Student Performance and Retention at a Minority Institution", presented at the 2009 ASEE Annual Conference

4. E. Cooney, "Laboratory Report Grading Rubrics: What High School Teachers are Doing", presented at the 2002 ASEE Annual Conference

5. R. Kellogg, J. Mann, and A. Dieterich, "Developing and Using Rubrics to Evaluate Subjective Engineering Laboratory and Design Reports", presented at the 2001 ASEE Annual Conference

6. R.Ryan, N. Ho, and S. Bartenstein, "Development of an Assessment Plan for a New Sequence of Design Courses", presented at the 2010 ASEE Annual Conference 